This is the peer reviewed version of the following article: Agliardi, Elettra, Agliardi, Rossella and Spanjers, Willem (2015) Convertible debt : financing decisions and voluntary conversion under ambiguity. International Review Of Finance, ISSN (print) 1369-412X, which has been published in final form at http://dx.doi.org/10.1111/irfi.12057 


\title{
CONVERTIBLE DEBT: \\ FINANCING DECISIONS AND VOLUNTARY CONVERSION UNDER AMBIGUITY
}

\author{
Elettra Agliardi \\ Department of Economics \\ University of Bologna, Bologna, Italy \\ email: elettra.agliardi@unibo.it \\ Rossella Agliardi \\ Department of Mathematics \\ University of Bologna, Bologna, Italy \\ email: rossella.agliardi@unibo.it \\ Willem Spanjers \\ Department of Economics \\ Kingston University, \\ Kingston-upon-Thames, United Kingdom \\ email: w.spanjers@kingston.ac.uk
}

\begin{abstract}
This paper integrates ambiguity into a contingent claim model for convertible debt. We study how convertible debt valuation is affected by the ambiguity biases of equity holders and debt holders and provide sensitivity analysis of the bond value to changes in attitude toward ambiguity, firm and bond parameters. Our results, which are summarized into six main predictions, are consistent with recent empirical evidence and offer a possible interpretation of some corporate finance puzzles.
\end{abstract}

Key words: convertible bonds; optimal default; stochastic optimization; ambiguity aversion; Choquet-Brownian process. 


\section{CONVERTIBLE DEBT: FINANCING DECISIONS AND VOLUNTARY CONVERSION UNDER AMBIGUITY}

Convertibles occupy an important place in the international financial market ${ }^{1}$. A convertible debt contract gives the bond holder the option to convert the bond into another security, usually the common stock of the issuing company. It has been argued at length that appropriately designed convertible debt can reduce classical risk-shifting agency problems (both asset-substitution and debt overhang) between equity holders and debt holders (see, f.e., Green, 1984; Brennan and Schwartz, 1987; Chakraborty and Yilmaz, 2011; Dorion, Francois, Grass and Jeanneret, 2014). Convertibles seem particularly well suited to control risk incentives, because of their relative insensitivity to the risk of the issuing firm value. In fact, convertible bonds align the objectives of firm and equity value maximization, being hybrid securities that, while retaining most of the characteristics of straight debt, add the upside potential of the underlying common stock, which is associated with the conversion or equity option. Thus, these claims impose a particular shape of the payoff function of equity, which alters the incentives of the equity holders to take risk. At the same time, asymmetric information between managers and investors may affect the relative mispricing of debt, equity and thus convertible debt. When the manager has private information, he/she has an incentive to issue a security that is overpriced in the market. Similarly to the pecking-order theory (Myers and Majluf, 1984), if equity is undervalued, convertible debt is less undervalued and thus a less costly source of funds, although more costly than straight debt; if equity is overvalued, then convertible debt will be also overvalued, but remains less costly than straight debt (Brennan and Schwartz, 1987). Hence, convertible debt may emerge as an optimal security, depending on the different forms of asymmetric information and beliefs of the investors.

In this paper we incorporate ambiguity (or, incalculable uncertainty ${ }^{2}$ ) and the investors' attitude towards it. The introduction of ambiguity into corporate finance decisions is a rather new and unexplored field and allows for more realistic features and explanations of still unanswered puzzles, while dealing with financial decisions (Garlappi, Gianmarino and Lazrak, 2013; Agliardi, Agliardi and Spanjers, 2014). Issuers and investors may differ in their prior beliefs and have different reactions to market signals

\footnotetext{
${ }^{1}$ The total size of the convertibles was on average US\$500bn per year during 2008- 2012 with around 2500 issues. This was about 1.5 the size of the FTSE 250 Index and equated approximately the 2007-2011 US high yield bond market issuance (US\$591bn). In 2014 the total size of convertibles of US\$268bn from 2346 issuers has become only a small fraction of the US\$9.6 trillion corporate bonds outstanding from almost 7000 issuers (BofA Merrill Lynch, 2014; Fitch Ratings' Report: CB Funds Dashboard 2014), but the available evidence shows a growing global convertible market also in developing countries (issuance volumes in Asia jumped fivefold in 2014, largely driven by China, source: Thomson Reuters, 2015).

${ }^{2}$ For a definition of ambiguity see, for example, Epstein and Schneider (2010). Loosely speaking, while risk relates to known uncertainty (that is, the probabilities are known or can be estimated with confidence), ambiguity refers to subjective uncertainty (where outcome probabilities are unknown, or there is uncertainty over the probability measure governing the outcomes).
} 
under ambiguity or partial ignorance, as emphasized by recent contributions within a behavioural perspective (Shefrin, 2009), a "managerial personality" traits view (Hackbarth, 2008), or the organizational real option approach (Trigeorgis, 2014). Behavioural biases and personality flaws (optimism/pessimism and over/underconfidence), which may include the attitude towards ambiguity, may lead to distortions and deviations from the true asset values and lead to decision "mistakes" (see Driouchi, Trigeorgis and Gao, 2014). In this paper we study how convertible debt valuation is affected by the ambiguity biases of equity holders and debt holders and provide some implications, summarized in five Predictions, on the effects of changes in relevant parameters on debt valuation and the conversion decision. To our knowledge, this is the first study integrating ambiguity into a structural model for convertible bonds, to analyse what happens when decision-makers are rational in all aspects, except for how they perceive the firm's future. The behavioural biases impact on firm's financing decisions and on the prices of corporate securities.

\section{The Model}

Let us suppose that the firm's assets in place generate a random stream of EBIT, $V_{t}$, which follows a Choquet-Brownian process It is defined on the basis of a binomial lattice, where for each $s_{t}$ at time $t$, such that $0 \leq t \leq T, s_{t+1}{ }^{u}$ and $s_{t+1}{ }^{d}$ denote the possible successors at time $t+1$ for an "up" and a "down" movement, respectively. If "up" and "down" movements have the same capacity, then $v\left(s_{t}{ }^{u} \mid S_{t}\right)=v\left(s_{t}{ }^{d} \mid s_{t}\right)$ $=c$, where $c, 0<c<1$, is a constant that represents the decision-maker (hereafter DM)'s ambiguity about the likelihood of the states to come. If the DM is ambiguity averse, the capacity is sub-linear, so that $c<1 / 2$ (Gilboa, Postlewaite and Schmeidler, 2008). If the perceived ambiguity increases, the value of the parameter $c$ moves further away from the anchor $1 / 2$. Thus, the capacity becomes more convex (for an ambiguity averse DM) or more concave (for an ambiguity loving DM). The absence of an ambiguity bias is obtained as a special case for $c=1 / 2$. The symmetric discrete process above can be shown to converge (see Kast, Lapied and Roubaud, 2014) to a continuous time generalized Wiener process with mean $m=2 c-1$ and variance $s^{2}=4 c(1-c)$. Thus, the firm's EBIT value is given by:

$$
d V_{t} / V_{t}=(\mu+m \sigma) d t+s \sigma d B_{t}
$$

where $B_{t}$ is a Wiener process, $\mu+m \sigma$ denotes the expected growth rate of EBIT and $s \sigma$ is the volatility per unit of time, as perceived by a biased DM. For fully ambiguity averse DMs we have $-1<m<0$ and $0<s<1$, so $\mu+m \sigma<\mu$ and $0<s \sigma<\sigma$. Both drift and volatility are reduced in comparison to the case of absence of ambiguity biases. We assume that the firm has straight debt and convertible debt outstanding, both with infinite maturity, in addition to equity. By $C$ we denote the instantaneous coupon paid to holders of straight debt and by $K$ the instantaneous coupon paid to holders of convertible debt. If 
all convertible debt is converted into equity, convertible debt holders will get a fraction $\frac{\psi}{1+\psi}$ of equity, where $\psi$ denotes the ratio of the number of shares owned by convertible bondholders upon full conversion to the number of shares owned by the initial shareholders. For simplicity, we suppose that the conversion terms of the convertible security are constant over time. As Ingersoll (1977) explains, while dealing with convertible issues in aggregate, the terms of conversion can be expressed by a dilution factor, indicating the fraction of the common equity which would be held by the convertible issue's owners if the entire issue were converted. Here the dilution factor for equity holders is measured by $\frac{1}{1+\psi}$, which is incurred upon conversion. For simplicity, block conversion is assumed, that is, all convertible debt holders exercise their conversion option at the same time, as in Brennan and Schwartz (1977), Constantinides and Grundy (1984), and others. The firm uses net EBIT to make the coupon payments or to pay equity holders' dividends. When EBIT net of coupon payments is not sufficient, the equity holders finance this gap, unless they decide to declare bankruptcy, in which case, a fraction $\Theta$ $\in[0,1]$ of the value of assets is lost due to direct and indirect bankruptcy costs. Finally, in the basic model we do not add any call strategy, since we wish to separate the pure effects on voluntary conversion from a call induced conversion. Some implications of corporate call policies in our setting will be discussed in Section 2.

There are two optimization problems faced by equity holders and debt holders. The holders of convertible debt optimally choose the conversion threshold $V_{k}$. Conversion is voluntary. The benefit of conversion is the possibility of taking advantage of the upside potential of equity and receiving the dividend stream that may be higher than convertible coupon, while the cost of conversion is to give up the option of conversion. The firm's equity holders optimally select the default thresholds: let us denote by $V_{s d}$ the post-conversion default threshold (that is, the default threshold with straight debt only, after conversion occurred), and by $V_{c d}$ the pre-conversion default threshold (that is, the default threshold with both straight debt and convertible debt, before conversion occurred). We denote the value of equity by $E(V)$, the value of straight debt by $D(V)$ and the value of convertible debt by $B(V)$. The standard contingent claims argument applied to biased equity holders, maximizing the perceived (subjective) value of equity, allows us to derive the value of equity before conversion by solving the following ODE:

$$
\frac{1}{2} s^{2} \sigma^{2} V^{2} E^{\prime \prime}(V)+(\mu+m \sigma) V E^{\prime}(V)+V-K-C-r E(V)=0
$$

where $r$ is the discount rate. It yields: 


$$
E(V)=X V^{\beta_{1}}+Y V^{\beta_{2}}+\frac{V}{\phi}-\frac{K+C}{r}
$$

setting $\phi=r-(\mu+m \sigma)$, and $\beta_{1,2}=\frac{(\mu+m \sigma)-\frac{s^{2} \sigma^{2}}{2} \pm \sqrt{\left[\frac{s^{2} \sigma^{2}}{2}-(\mu+m \sigma)\right]^{2}+2 s^{2} \sigma^{2} r}}{s^{2} \sigma^{2}}$, where $\beta_{1}$ is positive and $\beta_{2}$ is negative. Similarly, we can find the values of straight debt $D(V)$ and of convertible debt $B(V)$ before conversion. For simplicity, let us suppose that debt holders have the same perceived ambiguity of equity holders. In Section 3 we examine also the case where the perceived ambiguity values of debt holders may differ from the equity holders', which implies that the $m$ and $s$ parameters may differ. Since $B(V)=F V^{\beta_{1}}+G V^{\beta_{2}}+\frac{K}{r}$, we can show that the optimal post-conversion default threshold is: $V_{s d}=\frac{\beta_{2}}{\beta_{2}-1} \frac{C \phi}{r}$, and hence the equity value with straight debt only is $E_{\text {straight }}(V)=\frac{V}{\phi}-\frac{C}{r}-\left(\frac{V}{V_{s d}}\right)^{\beta_{2}}\left(\frac{V_{s d}}{\phi}-\frac{C}{r}\right)$. The coefficients $X, Y, F$ and $G$, together with the optimal default threshold $V_{c d}$ and the conversion threshold $V_{k}$, can be obtained by the following system of equations:

$$
\begin{aligned}
& X V_{c d}^{\beta_{1}}+Y V_{c d}^{\beta_{2}}+\frac{V_{c d}}{\phi}-\frac{K+C}{r}=0 \\
& X \beta_{1} V_{c d}^{\beta_{1}-1}+Y \beta_{2} V_{c d}^{\beta_{2}-1}+\frac{1}{\phi}=0 \\
& X V_{k}^{\beta_{1}}+Y V_{k}^{\beta_{2}}+\frac{V_{k}}{\phi}-\frac{K+C}{r}=\frac{1}{1+\Psi}\left[\frac{V_{k}}{\phi}-\frac{C}{r}-\left(\frac{V_{k}}{V_{s d}}\right)^{\beta_{2}}\left(\frac{V_{s d}}{\phi}-\frac{C}{r}\right)\right] \\
& F V_{k}^{\beta_{1}}+G V_{k}^{\beta_{2}}+\frac{K}{r}=\frac{\Psi}{1+\Psi}\left[\frac{V_{k}}{\phi}-\frac{C}{r}-\left(\frac{V_{k}}{V_{s d}}\right)^{\beta_{2}}\left(\frac{V_{s d}}{\phi}-\frac{C}{r}\right)\right] \\
& F \beta_{1} V_{k}^{\beta_{1}-1}+G \beta_{2} V_{k}^{\beta_{2}-1}=\frac{\Psi}{1+\Psi}\left[\frac{1}{\phi}-\beta_{2}\left(\frac{V_{k}}{V_{s d}}\right)^{\beta_{2}-1}\left(\frac{V_{s d}}{\phi}-\frac{C}{r}\right)\right] \\
& F V_{c d}^{\beta_{1}}+G V_{c d}^{\beta_{2}}+\frac{K}{r}=(1-\Theta) \frac{K}{C+K} \frac{V_{c d}}{\phi}
\end{aligned}
$$

Conditions (4) and (5) are the value-matching and smooth-pasting conditions set by equity holders at default, such that equity equals zero at default, while condition (6) establishes that the value of equity at the optimal conversion threshold must equal the value of the newly issued equity, accrued by equity 
holders after conversion and taking into account equity dilution (i.e., given the fraction $\frac{1}{1+\Psi}$ ). Conditions (7) and (8) are the value-matching and smooth-pasting conditions set by debt holders, ensuring that the value of a convertible bond equals the fraction of the value of equity obtained after conversion, given the fraction $\frac{\Psi}{1+\Psi}$. Finally, condition (9) shows that the convertible debt holders' claim equals the firm's abandonment value, net of bankruptcy costs, at default (see also Lyandres and Zhdanov, 2014). By computation on (4), (5), (7) and (8) we can obtain the following expressions:

$$
\begin{aligned}
& X=\frac{1}{\beta_{1}-\beta_{2}}\left\{-\beta_{2} \frac{K+C}{r}-\frac{V_{c d}}{\phi}\left(1-\beta_{2}\right)\right\} V_{c d}^{-\beta_{1}} \\
& Y=\frac{1}{\beta_{1}-\beta_{2}}\left\{\beta_{1} \frac{K+C}{r}+\frac{V_{c d}}{\phi}\left(1-\beta_{1}\right)\right\} V_{c d}^{-\beta_{2}} \\
& G=\frac{1}{\beta_{2}-\beta_{1}}\left\{\beta_{1} \frac{K}{r}+\frac{\Psi}{1+\Psi}\left(\frac{V_{k}}{\phi}\left(1-\beta_{1}\right)+\frac{C}{r} \beta_{1}\right\} V_{k}^{-\beta_{2}}-\frac{\Psi}{1+\Psi}\left(\frac{V_{s d}}{\phi}-\frac{C}{r}\right) V_{s d}^{-\beta_{2}}\right. \\
& F=\frac{1}{\beta_{1}-\beta_{2}}\left\{\beta_{2} \frac{K}{r}+\frac{\Psi}{1+\Psi}\left(\frac{V_{k}}{\phi}\left(1-\beta_{2}\right)+\frac{C}{r} \beta_{2}\right\} V_{k}^{-\beta_{1}}\right.
\end{aligned}
$$

By plugging the expressions of $X, Y, G$ and $F$ into (6) and (9) we obtain the values of $V_{k}$ and $V_{c d}$, which can be solved numerically.

Let us examine the effects of variation in selected parameters on the relationship between the value of convertible debt and EBIT. The base case parameters, characterizing a representative firm are as follows: $r=0.04, \mu=0.01, C=0.1, K=0.08, \sigma=0.2, \Psi=1$.

Figure 1 shows the value of convertible debt as ambiguity perceived by ambiguity averse claimholders changes $(c=0.5 ; c=0.4 ; c=0.3)$. Convertible debt holders participate in the firm's upside potential if asset values are high enough to make the conversion valuable. Convertible debt financing affects the payoffs and thus equity valuation: old equity holders must share the payoffs with the new equity holders, as new equity is issued and existing equity is diluted. Figure 1 shows that the conversion threshold is always bigger than the default threshold and both thresholds increase as ambiguity perceived by ambiguity averse claimholders increases (that is, $c$ decreases). Thus, convertibles issued by less ambiguity averse firms should have a lower conversion threshold. A comparison between the post-conversion threshold $V_{s d}$ and the pre-conversion threshold $V_{c d}$ shows that $V_{s d}<V_{c d}$, for all 
parameter values ${ }^{3}$, implying that convertibles improve the solvability of the firm, delaying default. This result seems to be consistent with empirical findings by Isagawa (2002) and Dutordoir, Strong and Ziegan (2014), showing that convertibles alleviate firms' financial distress and are perceived as more valuable for firms with weaker corporate governance and higher distress costs. Prediction 1 summarizes these implications.

Prediction 1. Conversion occurs at a higher conversion threshold if ambiguity perceived by ambiguity averse claimholders increases. Default is anticipated as perceived ambiguity increases, but the presence of convertibles alleviates firm's distress.

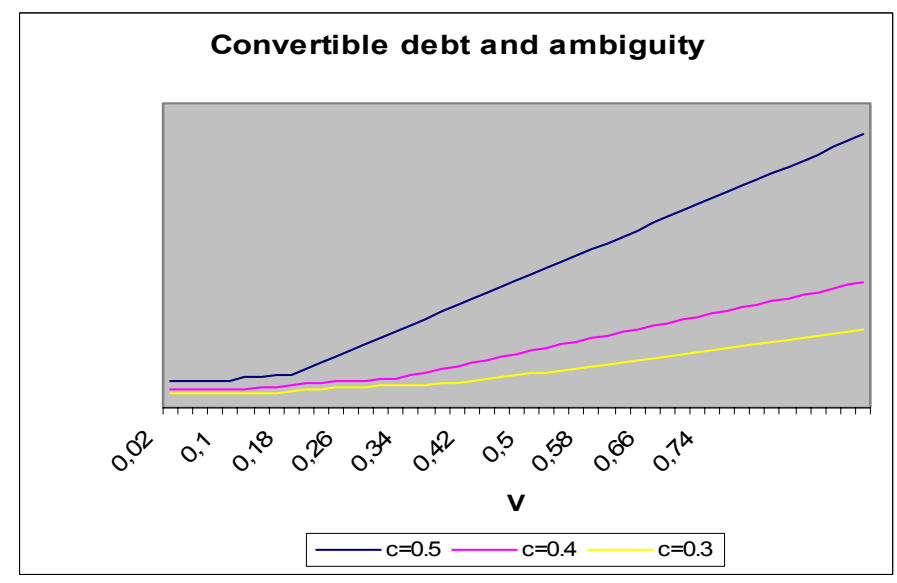

Figure 1: $r=0.04, \mu=0.01, C=0.1, K=0.08, \sigma=0.2, \Psi=1$

Numerical computations (not reported for brevity) show that Prediction 1 is preserved, if we change the conversion terms, i.e., the fraction of the firm's shares into which the bond is convertible, although the value of convertible debt decreases as the conversion ratio decreases. One can show that the value of convertible debt decreases as volatility increases up to a value of EBIT, then it increases as volatility increases, that is, there is a single-crossing behavior. An increase in volatility both raises the expected loss through default, as for straight debt, and increases the expected gain from conversion. The former effect decreases the bond value, while the latter affects the conversion option, increasing the bond value. For low values of EBIT, the former effect prevails and therefore debt decreases as volatility increases. For large EBIT values the latter effect prevails, and the equity-like component, associated with conversion, becomes apparent. Convertible debt should be less sensitive to changes in volatility than straight debt, because the value of the convertible debt component decreases in volatility, while the

\footnotetext{
${ }^{3}$ For example, for $c=0.5$ we get $V_{s d}=0.046, V_{c d}=0.092$; for $c=0.4$ we get $V_{s d}=0.07, V_{c d}=0.13$; for $c=0.3$ we get $V_{s d}=0.082, V_{c d}=0.15$
} 
equity-like component increases. Notice that this effect is completely different from the effect of ambiguity. Prediction 2 summarizes this implication:

Prediction 2. For low (high) values of EBIT, convertible debt value decreases (increases) as volatility increases.

Figure 2 shows the changes in the conversion and default thresholds for two different levels of ambiguity aversion ( $c=0.5$ and $c=0.3$ ), as the coupon rate $K$ of the convertible debt changes. Both the conversion and the default thresholds increase with the coupon rate $K$. A higher coupon makes default more likely (i.e., the default threshold increases) and makes the conversion option less valuable, since debt holders are prior claimants over equity holders at default. As a result, the conversion threshold increases, that is, it must be higher to make the conversion worthy to the holders of a convertible bond. On the other hand, for a given coupon, both thresholds are lifted upwards in the presence of a higher degree of ambiguity aversion, as discussed in Prediction 1.

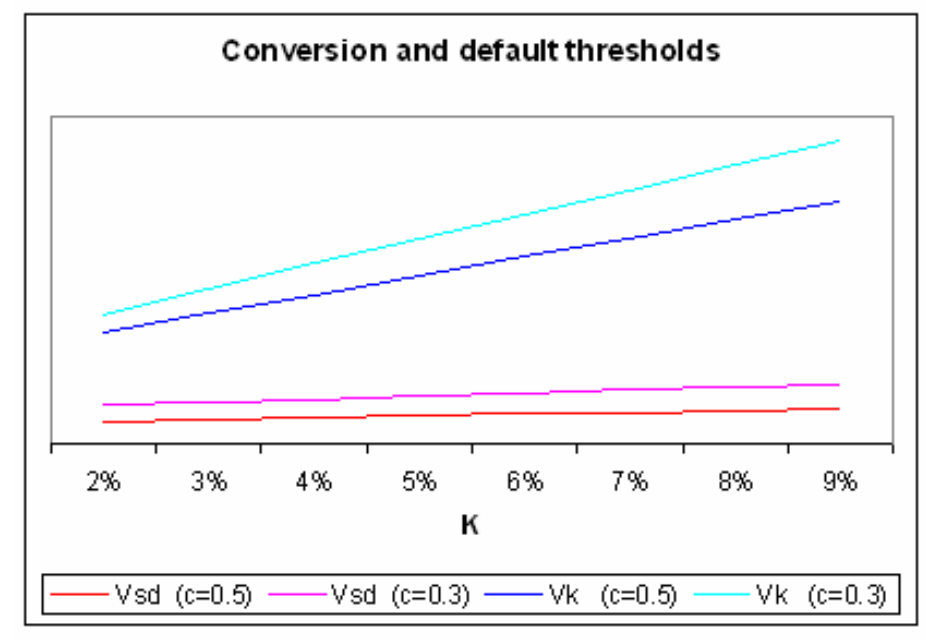

Figure 2: $r=0.04, \mu=0.01, C=0.1, \sigma=0.2, \Psi=1$

Figure 3 shows the ratio between the equity value and the price of the convertible bond for three different levels of $c$. Here $\Psi=1$, which yields a common ratio equal to 2 beyond the conversion thresholds. For all other levels of $V$, before conversion, this ratio decreases as ambiguity perceived by ambiguity averse claimholders increases, implying that equity becomes more (relatively) undervalued. Thus, equity holders prefer issuing convertible debt instead of equity as perceived ambiguity increases, which is consistent with a sort of pecking order prediction of financing decisions under ambiguity: equity holders rely on internal capital and debt first, and use equity only as a last resort. Thus, we get the following:

Prediction 3. If claimholders agree on the same level of perceived ambiguity, then an increase in ambiguity aversion leads to aversion to equity. 
If there is disagreement over ambiguity, say between the decision-maker and the market, such that, for example, the market's valuation is not biased by ambiguity aversion $(c=0.5)$, while the manager believes that EBIT is described by expression (1) with $\mathrm{c}<0.5$, and therefore believes that equity is more overvalued by the market than convertible debt (because $\mathrm{E}(\mathrm{V}) / \mathrm{B}(\mathrm{V})$ for $c<0.5$ is less than for $c=0.5$, see Figure 3), then the manager may wish to issue equity, reversing the pecking order. Therefore, the theoretical predictions about the effects of ambiguity on capital structure are somewhat sensitive to the modeling framework and the divergence in ambiguity assessment.

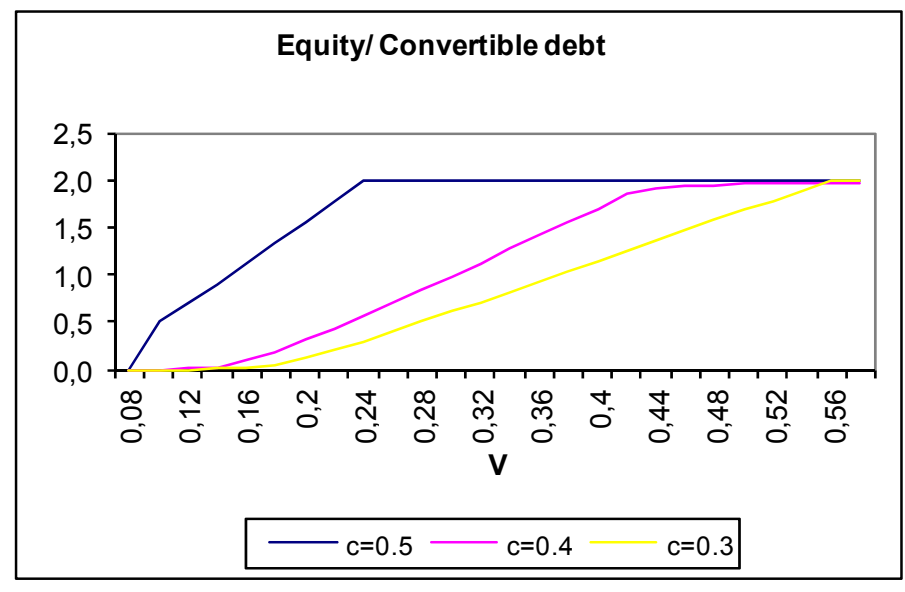

Figure 3: $r=0.04, \mu=0.01, C=0.1, K=0.08, \sigma=0.2, \Psi=1$

\section{Call provision}

There is a vast literature studying corporate call policies for convertible bonds (see, f.e. Brennan and Schwartz, 1977; Ingersoll, 1977; Chakraborty and Yilmaz, 2011; King and Mauer, 2014). Since the theoretical models by Ingersoll (1977) and Brennan and Schwartz (1977), the appropriate (optimal) policy - i.e., the policy that minimizes the value of the conversion option and thus maximizes equity is to call as soon as the value of the convertible bond reaches the call price, that is, when the conversion value of the bond equals the call price. This puts an upper boundary to the value of debt, which in our framework modifies expression (7) into the following:

$$
F V_{k}^{\beta_{1}}+G V_{k}^{\beta_{2}}+\frac{K}{r}=\max \left(\frac{\Psi}{1+\Psi}\left[\frac{V_{k}}{\phi}-\frac{C}{r}-\left(\frac{V_{k}}{V_{s d}}\right)^{\beta_{2}}\left(\frac{V_{s d}}{\phi}-\frac{C}{r}\right)\right], \mathrm{CP}\right)
$$

where CP stands for the corresponding call price. Empirical studies, however, show that the actual call policies do not even approximate the optimal policy. Actually, "convertibles are not generally called until their premium over the call price is significantly larger" (Brennan and Schwartz, 1987), and the motive for this deferred conversion remains a puzzle (see King and Mauer, 2014, and references there). Although we are aware that the empirical literature has tried to explain such discrepancy by various 
determinants (e.g., tax-based razionalization of corporate call policies, as in the "cash flow advantage" hypothesis, management concern about future selling of convertibles and observed stock price implications, growth and sequential financing motives, as in the "backdoor equity" hypothesis) ${ }^{4}$, here we propose an interpretation of this delay in terms of an ambiguity effect.

Indeed, let us focus on expression (14). Since $V_{k}$ increases as perceived ambiguity increases, as from Prediction 1, CP in expression (14) is unlikely to be binding, whenever ambiguity is high, and thus, the issuer of a convertible bond is more prone to defer the call. The puzzle of a late call may be eventually attributed to a behaviour consistent with higher perceived ambiguity. We can summarize this implication as follows:

\section{Prediction 4. Firms with higher ambiguity aversion tend to delay calling to force conversion.}

This seems to be consistent with some empirical findings of a positive relation between call delay and excess cash balances due to a cautious attitude (see King and Mauer, 2014).

\section{Asymmetric perceived ambiguity}

Even though equity holders and debt holders agree that assets are correctly priced in the market, so that there is no mispricing, there might be divergence in their ambiguity assessment. Let us suppose that the perceived ambiguity values of debt holders may differ from the equity holders', which implies that the $m$ and $s$ parameters may differ. In Table 1 we compare the default and the conversion thresholds in the symmetric case (that is, when equity holders and debt holders have the same perceived ambiguity) and in the asymmetric cases (that is, when equity holders are more ambiguity averse than debt holders, or in the reverse case). If equity holders are less ambiguity averse than debt holders, then $V_{k}$ increases more than when equity holders and debt holders have the same perceived ambiguity. On the other hand, if equity holders are more ambiguity averse than debt holders, then $V_{k}$ decreases more than when equity holders and debt holders have the same perceived ambiguity. We can summarize this implication as follows:

\footnotetext{
${ }^{4}$ The "cash flow advantage hypothesis" states that conversion will (not) be called if the cash flow advantage of a convertible bond, measured by the difference between the dividend on the converted shares and the after tax coupon on the bond is negative (positive). A number of empirical studies since Brennan and Schwartz (1977) found that firms that call their convertible bonds experience a negative stock price reaction. This finding fostered an interpretation of this negative announcement effect in terms of bad news signaling, so that giving up or delaying to force conversion is a signal of favourable inside information. Finally, the "backdoor equity" hypothesis argues that firms issue convertible bonds just as a substitute for equity, so that, in particular, a firm will force conversion to equity when it chooses to exercise its growth options.
} 
Prediction 5. As perceived ambiguity increases, and debt holders are more (less) ambiguity averse than equity holders, conversion occurs at a higher (lower) EBIT threshold than in the case of symmetric ambiguity.

Table 1

\begin{tabular}{|c|c|c|c|c|}
\hline & & & $V_{c d}$ & $V_{k}$ \\
\hline $\begin{array}{l}\text { Symmetric } \\
\text { equity holders } \\
\text { and debt holders }\end{array}$ & $\begin{array}{l}c= \\
c= \\
c=\end{array}$ & & $\begin{array}{l}0.092 \\
0.13 \\
0.15\end{array}$ & $\begin{array}{l}0.42 \\
0.47 \\
0.50\end{array}$ \\
\hline $\begin{array}{l}\text { Asymmetric } \\
\text { equity holders } \\
\text { and debt holders }\end{array}$ & 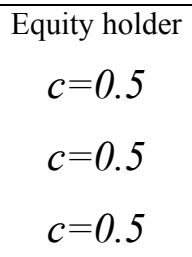 & $\begin{array}{c}\text { Debt holder } \\
c=0.5 \\
c=0.4 \\
c=0.3\end{array}$ & $\begin{array}{l}0.092 \\
0.092 \\
0.092\end{array}$ & $\begin{array}{l}0.42 \\
0.52 \\
0.62\end{array}$ \\
\hline $\begin{array}{l}\text { Asymmetric } \\
\text { equity holders } \\
\text { and debt holders }\end{array}$ & 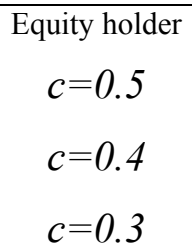 & $\begin{array}{c}\text { Debt holder } \\
c=0.5 \\
c=0.5 \\
c=0.5\end{array}$ & $\begin{array}{l}0.092 \\
0.13 \\
0.15\end{array}$ & $\begin{array}{l}0.42 \\
0.34 \\
0.28\end{array}$ \\
\hline
\end{tabular}

\section{Conclusion}

Convertible bonds are an important segment of the corporate bond market, with total outstanding above US $\$ 250$ billion. Over the last decades a considerable amount of theoretical research and empirical studies focused on why firms issue convertibles, and, notwithstanding a variety of explanations, some puzzles remain, at least partially, unsolved. This paper is a first attempt at linking convertible debt valuation to behavioural biases and personality flaws of managers and investors. We integrate ambiguity and attitude toward ambiguity into a contingent claim model for convertible debt. We study how convertible debt valuation is affected by the ambiguity biases of equity holders and debt holders and provide sensitivity analysis of the bond value to changes in attitude toward ambiguity, firm and bond parameters. Our results, which are summarized into five main predictions, are consistent with recent empirical evidence and offer a possible interpretation of some corporate finance puzzles.

\section{References}

Agliardi, E., Agliardi, R. and W. Spanjers, 2014, Cash Holdings and Financing Decisions under Ambiguity, DSE Working Paper 979 and http://ssrn.com/abstract=2526704

Brennan, M.J. and E.S. Schwartz, 1977, Convertible Bonds: Valuation and Optimal Strategies for Call and Conversion, The Journal of Finance, 1699-1715 
Brennan, MJ and E.S Schwartz, 1987, The Case for Convertibles, Journal of Applied Corporate Finance, 55-64

Chakraborty, A. and B. Yilmaz, 2011, Adverse Selection and Convertible Bonds, Review of Economic Studies, 148-175

Constantinides, G.M. and B.D. Grundy, 1989, Optimal investment with stock repurchase and financing as signals, Review of Financial Studies, 445-465

Dorion, C. Francois, P., Grass, G. and A. Jeanneret, 2014, Convertible Debt and Shareholder Incentives, Journal of Corporate Finance, 38-56

Dutordoir, M., Strong, N. and M.C. Ziegan, 2014, Does Corporate Governance influence Convertible Bond Issuance? Journal of Corporate Finance, 80-100

Epstein, L. and M. Schneider, 2010, Ambiguity and asset Markets, Annual Review of Financial Economics, 315-346

Garlappi L, Giammarino R. and A. Lazsak, 2013, Ambiguity in Corporate Finance: Real Investment Dynamics, mimeo

Gilboa, I., A. Postlewaite and D. Schmeidler, 2008, 'Probability and Uncertainty in Economic Modelling', Journal of Economic Perspectives, 173 - 188.

Green, R, 1984, Investment Incentives, Debt and Warrants, Journal of Financial Economics, 115-136

Hackbarth, D. , 2008, Managerial Traits and Capital Structure Decisions, Journal of Financial and Quantitative Analysis, 43, 843 - 882.

Ingersoll, J.E., 1977, A Contingent-Claims Valuation of Convertible securities, Journal of Financial Economics, 289-322

Isagawa, N. 2002, Callable Convertible Debt under managerial Entrenchment, Journal of Corporate Finance, 8, 255-270

Kast, R, A. Lapied and D. Roubaud (2014), Modelling under ambiguity with dynamically consistent Choquet random walks and Choquet-Brownian motions, Economic Modelling, 495-503.

King, T-H, D and D.C. Mauer, 2014, Determinants of Corporate Call Policy for Convertible Bonds, Journal of Corporate Finance, 112-134

Lyandres, E. and A. Zhdanov, 2014, Convertible debt and investment timing, Journal of Corporate Finance, 21-37

Myers, S. and N. Majluf, 1984, Corporate Financing and Investment Decisions when Firms have Information that Investors do not have, Journal of Financial Economics, 13, $187-221$.

Shefrin, H., 2009, Behaviouralizing Finance, Foundations and Trends in Finance, vol. 4, 1-2, 1-184

Trigeorgis, L, 2014, Real options Theory for Real Organizations: Partial Ignorance, Beliefs, Behavioural Biases, Overconfidence, Bounded Rationality and Adaptive Learning, mimeo 